\section{Review Article}

Clinical Chemistry

Ann Lab Med 2020;40:101-113

https://doi.org/10.3343/alm.2020.40.2.101

Check tor
supdates

ISSN 2234-3806 elSSN 2234-3814

\title{
Laboratory Monitoring of Biological Therapies in Rheumatology: The Role of Immunogenicity
}

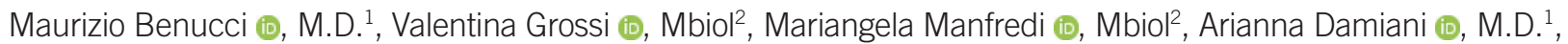

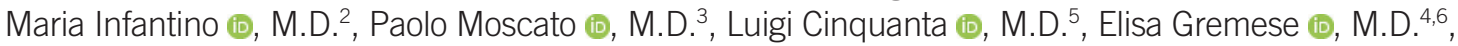

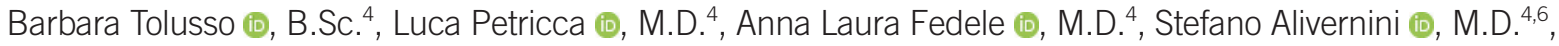

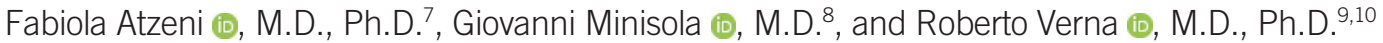

${ }^{1}$ Rheumatology Unit and ${ }^{2}$ Immunology and Allergology Laboratory Unit, S.Giovanni di Dio Hospital, Florence, Italy; ${ }^{3}$ Department of Medicine, University Hospital San Giovanni di Dio e Ruggi d'Aragona, Salerno, Italy; “ Division of Rheumatology, Fondazione Policlinico Universitario A. Gemelli, IRCCS, Rome, Italy; ${ }^{5}$ SDN SPA-Synlab Laboratory, Pagani, Salerno, Italy; ${ }^{6}$ Division of Rheumatology, Università Cattolica del Sacro Cuore, Rome, Italy; ${ }^{7}$ Rheumatology Unit, University of Messina, Messina, Italy; ${ }^{8}$ Italian Society of Rheumatology, Milan, Italy; ${ }^{9}$ World Association of Societies of Pathology and Laboratory Medicine, Milan, Italy; ${ }^{10}$ Department of Experimental Medicine Sapienza University of Rome, Rome, Italy
\end{abstract}

Biological drugs, such as proteins and immunogens, are increasingly used to treat various diseases, including tumors and autoimmune diseases, and biological molecules have almost completely replaced synthetic drugs in rheumatology. Although biological treatments such as anti-tumor necrosis factor (TNF) drugs seem to be quite safe, they cause some undesirable effects, such as the onset of infections due to weakening of the immune system. Given the biological nature of these drugs, they might be recognized as extraneous; this would induce an immune reaction that neutralizes their effectiveness or lead to more serious consequences. Laboratories play a pivotal role in appropriate therapeutic management. The aim of this review was to underline the production of anti-drug antibodies during treatment with biological drugs and highlight the role of laboratories in ensuring appropriate use of these drugs.

Key Words: Anti-tumor necrosis factor (TNF) drugs, Antibodies, Anti-drug antibodies, Biological drugs
Received: March 4, 2019

Revision received: June 9, 2019

Accepted: October 15, 2019

\section{Corresponding author:}

Roberto Verna, M.D., Ph.D.

Department of Experimental Medicine,

Sapienza University of Rome, Viale Regina

Elena 324, Rome 00161, Italy

Tel: +393711547775

Fax: +0082313898817

E-mail: roberto.verna@fondazione.uniroma1.it

\section{(1) (\$)}

(c) Korean Society for Laboratory Medicine This is an Open Access article distributed under the terms of the Creative Commons Attribution Non-Commercial License (http://creativecommons.org/licenses/by-nc/4.0) which permits unrestricted non-commercial use, distribution, and reproduction in any medium, provided the original work is properly cited.

\section{INTRODUCTION}

The term "biological treatment" refers to a variety of treatments of natural origin (e.g., vaccines, blood, blood components, gene therapy, and recombinant proteins), but it has typically come to be used in relation to a subgroup of large, complex molecules used for targeted therapy, including monoclonal antibodies (moAbs) and receptor fusion proteins. Unlike small molecules, which have low molecular weight and are capable of crossing the cell membrane and acting intracellularly, these biological agents are high-molecular-weight proteins that have to be in- jected, because they would be degraded in the gastrointestinal tract if administered orally, and act on the cell surface or extracellularly. Furthermore, they are produced in specialized live cells, whereas small molecules are simpler and can be chemically synthesized.

The nomenclature of receptor fusion proteins and moAbs follows the rules of the International Nonproprietary Names selected by the World Health Organization. The suffix "-cept" is used to identify receptor molecules (e.g., etanercept [ETA]), whereas "-mab" is used to identify moAbs; antibodies of fully human origin have the addition of "-mu-" (e.g., adalimumab 
$[A D A])$, whereas those with both human and murine origin are humanized ("-zu-", e.g., ixekizumab) or chimeric ("-xi-", e.g., infliximab) [1]. Biological drugs were introduced into clinical practice nearly 20 years ago and have now become powerful means of treating patients with chronic immuno-inflammatory arthritis, such as rheumatoid arthritis (RA), juvenile idiopathic arthritis, psoriatic arthritis (PsA), and spondyloarthritis (SpA), including ankylosing spondylitis (AS) and non-radiographic axial SpA. They are a major alternative for patients with these conditions who do not respond to or tolerate conventional synthetic disease-modifying anti-rheumatic drugs (csDMARDs, such as methotrexate, sulfasalazine, and leflunomide). The biological drugs used to treat immuno-inflammatory arthritis are genetically engineered human proteins that inhibit specific components of the immune system involved in enhancing inflammation by neutralizing cytokines via soluble receptors or moAbs, receptor blockade, or anti-inflammatory pathway activation [2]. Table 1 shows the currently available biological agents for treatment of immuno-inflammatory arthritis. However, some patients fail to respond to initial treatment or lose responsiveness, and some patients have to discontinue the biological agents because of side effects.

Biological agents positively interfere with the structural damage associated with immuno-inflammatory rheumatic diseases, and they have an excellent risk/benefit profile as they significantly decrease cardiovascular risk and mortality. The choice of a specific agent for a particular patient mainly depends on clinical considerations, such as safety profile and dosing frequency of the candidate drug, the route and mode of administration, and the presence of comorbidities. However, it is also influenced by economic consideration, because of the high cost of these drugs and administrative restrictions. Thus, although they are highly effective in the treatment of rheumatic diseases and

Table 1 . The seven currently available classes of biological agents

\begin{tabular}{|c|c|}
\hline Biological Agent & Action \\
\hline $\begin{array}{l}\text { Adalimumab, certolizumab pegol, } \\
\text { etanercept, golimumab, infliximab }\end{array}$ & Tumor necrosis factor inhibition \\
\hline Anakinra & Interleukin-1 receptor antagonism \\
\hline Abatacept & $\begin{array}{l}\text { T cell costimulation inhibition (anti } \\
\text { CD80/86) }\end{array}$ \\
\hline Sarilumab, tocilizumab & Interleukin-6 receptor antagonism \\
\hline Ustekinumab & $\begin{array}{l}\text { The p40 subunit of interleukin-12/23 } \\
\text { inhibition }\end{array}$ \\
\hline Ixekizumab, secukinumab & Interleukin-17 inhibition \\
\hline Rituximab & B-cell depletion (anti-CD20) \\
\hline
\end{tabular}

can be considered cost-effective in patients not responding adequately to conventional treatment, biological agents are unlikely to be prescribed as a first-line or even second-line treatment.

"Biosimilars" have been introduced as a means of increasing access to biological treatment in a more affordable manner. According to the US Food and Drug Administration (FDA), a biosimilar is a pharmaceutical product that is highly similar to its reference product (RP, or originator) "notwithstanding minor differences in clinically inactive components"; therefore, there is "no clinically meaningful difference" between them in terms of safety, purity, or potency [3]. Biosimilars are produced in living systems using complex purification techniques and recombinant DNA technology, and they are pharmacokinetically bioequivalent to their originators [4]. They also require similar storage techniques and transport technology [4]. Originators and biosimilars have dramatically improved outcomes in rheumatic diseases for which they have been used, and have contributed to making remission a realistic target. In addition to being good alternatives for patients who cannot be treated with csDMARDs, they offer additional therapeutic choices for healthcare providers and patients. The competition between originators and biosimilars should increase access to biological treatments. However, challenges, such as the lack of long-term safety data and the need for biological registries, and questions concerning when and how to switch from an originator to a biosimilar remain and should be considered by rheumatologists.

\section{SERUM DRUG LEVELS, ANTI-DRUG ANTIBODIES, AND CLINICAL RESPONSES}

Several studies have evaluated the correlation between anti-tumor necrosis factor (TNF) drug antibodies, serum drug levels, and clinical responses (Table 2). The RISING study [5] as-

Table 2. Studies evaluating correlations between anti-TNF drug antibodies, serum drug levels, and clinical responses

\begin{tabular}{lcccc}
\hline Study & Molecules & Endpoint & Patients (N) & Medical centers \\
\hline RISING [5] & IFX+MTX & $\begin{array}{c}\text { Response in RA } \\
\text { patients }\end{array}$ & 334 & 88 in Japan \\
ATTRACT [7] & IFX+MTX & Active RA & 446 & NIH-sponsored \\
BRAGGSS [12] & ADA/ETA & Active RA & 311 & 60 in the UK \\
\hline
\end{tabular}

Abbreviations: TNF, tumor necrosis factor; IFX, infliximab; MTX, methotrexate; ADA, adalimumab; ETA, etanercept; RA, rheumatoid arthritis; $\mathrm{NIH}, \mathrm{Na}-$ tional Institute of Health; BRAGGSS, Biologics in Rheumatoid Arthritis Genetics and Genomics Study Syndicate. 
sessed the effect of infliximab (IFX) plus methotrexate (MTX) on radiographic and clinical responses in 334 patients with RA (including patients with active RA despite treatment with MTX for more than 12 weeks) attending 88 Japanese medical centers. It compared maximum (10 mg/kg) and minimum (3 mg/kg) IFX doses, and investigated whether the effects on responses were related to trough serum IFX levels. All the patients received 3 $\mathrm{mg} / \mathrm{kg}$ of IFX plus MTX in weeks zero, two, and six, after which they were randomized to receive 3,6 , or $10 \mathrm{mg} / \mathrm{kg}$ of IFX every eight weeks plus stable doses of MTX. The primary end points were the attainment of American College of Rheumatology (ACR) responses (ACR20, ACR50, and ACR70), a change in the 28-joint Disease Activity Score (DAS28), and a change in the European League Against Rheumatism (EULAR) response criteria. Radiographic progression was assessed using the Modified Total Sharp Score (TSS). Physical function was evaluated using the Health Assessment Questionnaire (HAQ). Trough serum IFX levels were measured by ELISA and a moAb against IFX, and were subsequently correlated with DAS28 and TSS results obtained in week 54 .

Of the 334 patients, 272 completed the study; the main causes of withdrawal from the study were adverse events, similar to those in the three treatment groups. Trough serum IFX levels in the 3, 6, and $10 \mathrm{mg} / \mathrm{kg}$ groups were $0.4,2.3$, and 5.5 $\mu \mathrm{g} / \mathrm{mL}$, respectively, indicating dose dependency, and were significantly associated with clinical response; a better EULAR response was observed in patients with higher trough serum levels $(P<0.0001)$. Higher trough serum levels were also observed in the patients achieving remission $(P<0.0001)$, and trough serum levels were significantly correlated with DAS28 remission $(P<0.0001)$. Patients with lower trough serum levels more frequently experienced progressive joint damage, and there was no improvement in their TSS; no joint damage progression was observed in the patients with trough serum IFX levels of $>10$ $\mu \mathrm{g} / \mathrm{mL}$. The inhibition of joint damage progression was directly related to the increase in trough serum IFX levels: the median trough serum level was $<0.1 \mu \mathrm{g} / \mathrm{mL}$ in non-responders and 1.1 $\mu \mathrm{g} / \mathrm{mL}$ in responders, suggesting that a trough serum level of $1.0 \mu \mathrm{g} / \mathrm{mL}$ is the threshold for a clinical response. Trough serum IFX levels are affected by serum clearance of IFX and the production of anti-IFX antibodies [6], which seems to have the greatest effect on the efficacy of IFX treatment. The relationship between trough serum IFX levels and the incidence of adverse events was not investigated.

The ATTRACT trial [7] aimed to establish the relationship between serum IFX levels and clinical improvement, and included
428 patients with active RA. IFX was administered at $3 \mathrm{mg} / \mathrm{kg}$ or $10 \mathrm{mg} / \mathrm{kg}$ every four or eight weeks in combination with weekly MTX (pharmacokinetic models were used to predict the trough serum levels of the doses not directly tested in the trial). Serum IFX levels were measured by ELISA one hour after infusion to approximate the maximum drug level. Trough serum levels directly correlated with the intravenous dose, with the group receiving $10 \mathrm{mg} / \mathrm{kg}$ having the highest median level, and a few patients having undetectable trough levels. Clinical improvement was measured using ACR20, ACR50, and ACR70 responses. The ACR20 response rate was similar in the treatment groups, whereas the ACR50 response rate was significantly lower in the group receiving $3 \mathrm{mg} / \mathrm{kg}$ every eight weeks; the highest proportions of ACR50 and ACR70 responses were observed in the patients with the highest trough serum IFX levels (both $P<0.001$ ). Serum levels were also correlated with laboratory measures and radiographic scores: higher trough levels were associated with a reduction in $\mathrm{C}$-reactive protein (CRP) levels $(P<0.001)$ and less progressive joint damage $(P=0.004)$. Within the groups, there was individual variability in serum IFX levels because of drug clearance; non-responders tended to eliminate IFX more rapidly than responders. The lack of a response to anti-TNF drugs is often due to the development of anti-drug moAbs, which reduces the treatment response and lead to treatment discontinuation [8, 9]. The 2013 research agenda of the EULAR task force for the management of RA included investigating whether serum drug and/or drug antibody levels are clinically useful variables [10]. When considering the results of immunogenicity studies, it is important to bear in mind that wide variation in anti-drug antibody frequency may be due to patient-related factors, associated treatments, such as the concomitant use of csDMARDs, differences in detection methods, and differences in free drug levels. RIAs seem to be less susceptible to drug interference than ELISAs [11], and drug interference can be avoided by using trough serum drug and antidrug antibody levels obtained immediately before the administration of the next scheduled dose.

The Biologics in Rheumatoid Arthritis Genetics and Genomics Study Syndicate (BRAGGSS) study [12] involved 311 patients with active RA enrolled from 60 centers in the UK and investigated treatment responses in relation to anti-drug antibodies. All the patients were prescribed ADA or ETA at enrollment, and serum levels and disease activity were measured after three, six, and 12 months during routine clinic visits. Therapeutic responses were evaluated using the EULAR response criteria and/ or a change in DAS28. Serum non-trough drug levels were 
tested in serial samples using ELISA. The presence of anti-drug antibodies was determined by RIA, with serum anti-drug antibody titers of $>12$ arbitrary units $(A U) / \mathrm{mL}$ being considered positive in both treatment groups. Anti-ADA antibodies were detected in $24.8 \%$ of the patients and were significantly associated with lower serum ADA levels $(P<0.0001)$. Most patients with anti-drug antibodies (90.3\%) developed immunogenicity within six months. The main baseline difference between the patients who developed anti-drug antibodies and those who did not was the median dose of MTX, which was significantly higher in the latter. Further, disease duration before biological treatment was longer in the patients with anti-drug antibodies.

Serum ADA levels and anti-ADA antibody status were significantly associated with a change in DAS28 after 12 months $(P<0.0001)$, whereas the 12 -month EULAR response was associated positively with serum ADA levels but negatively with anti-ADA antibody status. The ADA concentration-effect curve showed that a drug level of $<5 \mathrm{mg}$ was associated with a smaller change in DAS28, and that the optimal therapeutic window was 5-8 $\mu \mathrm{g} / \mathrm{mL}$; no EULAR response was observed in the patients with drug levels of $<0.1 \mathrm{mg}(P<0.0001)$. The strongest predictor of low drug levels over time was anti-drug antibody status $(P<0.003)$. Serum ETA levels were associated with a 12 -month EULAR response, but this association seemed to lose significance after adjusting the confounders of age, sex, body mass index (BMI), disease duration, and drug adherence. Moreover, the ETA concentration-effect curve did not reveal a clear therapeutic window to indicate an optimal treatment response. These results suggest that non-trough ADA and anti-ADA antibody status are useful for predicting no EULAR response after 12 months, whereas non-trough ETA levels are not. These findings are consistent with those of other studies demonstrating that treatment failure is higher in patients developing anti-drug antibodies to moAbs $[8,13]$. The study also showed an inverse correlation between anti-drug antibody and drug levels, suggesting that measuring anti-drug antibodies may be useful in orienting the therapeutic option in non-responders. Interestingly, the patients receiving lower MTX doses were more likely to develop immunogenicity. BMI and adherence also influenced drug pharmacokinetics and thus treatment responses.

ADA can induce anti-ADA antibodies, which are associated with low free drug levels and a clinical non-response. Most of the assays used to detect these antibodies may be affected by serum drug levels, but the sensitivity of an ELISA can be improved by using acid to dissociate the ADA-mAb immune complexes $[13,14]$. One study measured the clinical usefulness of acid dissociation by monitoring 238 serum samples taken every three to six months from 116 ADA-treated patients over a period of three years [15]. Trough serum ADA and anti-ADA antibody levels were measured by ELISA, and 32 samples from 22 patients with sub-therapeutic ADA levels were analyzed before and after acid dissociation. Before acid dissociation, these patients were found to be antibody-negative, but dissociation led to the detection of anti-ADA antibodies in 17 of the 32 samples. In case of low antibody titers, most of the antibodies are bound with the drug, whereas high titers lead to more free antibodies, which are easier to detect. Furthermore, the increase in antibody detection after acid dissociation is significant in the presence of low ADA levels. This means that acid dissociation may aid in clinical decision making in the case of a reduced response, as the presence of anti-ADA antibodies is one of the major causes of a loss of therapeutic effect.

ADA, IFX, and ETA can induce the development of anti-drug antibodies, which are also responsible for side effects, such as injection-site and infusion reactions, thromboembolic events, and serum sickness. Up to $44 \%$ of IFX-treated patients develop anti-IFX antibodies during the first six months of treatment [16, 17], and the same is true of up to $19 \%$ of ADA-treated patients [18]. The incidence of generally non-neutralizing anti-ETA antibodies is $0-7 \%$, and some studies failed to confirm the drug's immunogenicity $[8,19,20]$. One international, cross-sectional study assessed the immunogenicity of ETA, ADA, and IFX and its impact on trough serum drug levels and clinical responses in 600 patients with active RA divided into approximately equal treatment groups [21]. The patients were monitored by disease activity assessments, patient-reported outcomes, and trough serum drug (ELISA) and antidrug antibody (RIA) levels. The baseline characteristics and mean duration of treatment were similar in the three groups. None of the ETA-treated patients had detectable anti-ETA antibodies, whereas $31.2 \%$ of those treated with ADA and $17.4 \%$ of those treated with IFX did $(P<0.0001)$, indicating the greater immunogenicity of ADA and IFX. The incidence of anti-drug antibodies was higher in the patients treated for 6-12 months than in those treated for $12-18$ or $18-24$ months, and lower in those receiving concomitant MTX, although the difference between those who received and did not receive MTX was not statistically significant. Pooled data for all three TNF inhibitors showed that patients with low disease activity were more often negative for anti-drug antibodies: $66.5 \%$ of the patients treated with ETA, $64.5 \%$ of those treated with ADA (of whom $65.2 \%$ had no detectable antibodies), and $51.6 \%$ of those treated with IFX (of whom 53.3\% had no detectable anti- 
bodies). In total, $44.1 \%$ of patients were in remission, and a significant proportion of them $(44.1 \%, P=0.0046)$ were antibodynegative. Trough serum ADA and IFX levels were lower in the patients with detectable anti-drug antibodies $(80.5 \%$ and $98 \%$, respectively; $P<0.0001$ ). Composite disease activity measured based on the DAS28-erythrocyte sedimentation rate (ESR), DAS28-CRP, the Clinical Disease Activity Index, and the Simplified Disease Activity Index was relatively higher in the patients with detectable anti-drug antibodies. There was no significant difference in the proportion of patients with or without detectable anti-drug antibodies in the IFX and ADA groups. Overall, the patients treated with ADA or IFX who developed anti-drug antibodies had significantly lower trough serum drug levels and higher CRP levels and a higher ESR, but there was no significant correlation with DAS28-ESR remission or the Health Assessment Questionnaire Disability Index (HAQ-DI). However, trough serum ADA levels negatively correlated with DAS28-CRP, DAS28-ESR, HAQ-DI, Euro Quality of Life Health Status (EQ5D), and the 36-Item Short Form Health Survey (SF-36) general health score, indicating that lower trough serum ADA levelswhich may be due to the development of anti-drug antibodiesis related to greater disease activity and an impaired quality of life. In contrast, trough serum IFX levels did not significantly correlate with treatment efficacy or health outcome measures. In brief, although further prospective studies are required, these findings suggest that anti-drug antibodies develop in a higher proportion of patients receiving an anti-TNF moAb (ADA or IFX) than in those treated with a TNF receptor fusion protein (ETA). Furthermore, the presence of anti-ADA or anti-IFX antibodies is associated with lower serum drug levels and poorer efficacy outcomes. Treatment failure is more frequent in patients developing anti-drug antibodies to moAbs, and there is an inverse correlation between anti-drug antibodies and drug levels, suggesting that measuring anti-drug antibody levels may be useful in non-responders.

\section{IMMUNOGENICITY OF ANTI-TNF AGENTS IN RA}

bDMARDs, an important class of drugs that are frequently used to treat RA, have significantly reduced disease activity levels and improved the quality of life of patients who did not respond to csDMARDs [22]. However, up to $30 \%$ of the patients treated with bDMARDs show no or inadequate response to initial treatment (primary failure), and more than $30 \%$ of initial responders experience a loss of response over time (secondary failure) or develop potentially therapy-limiting adverse events [23].
Five anti-TNF agents have been licensed in Europe for the treatment of RA: IFX (a mouse-human chimeric moAb against TNF) and ETA since 1998; ADA since 2003; and, more recently, golimumab (GLM) and certolizumab pegol (CZP) [24]. Since the expiry of the patents of the first three anti-TNF agents, their biosimilars have also been used. All these anti-TNF drugs are high-molecular-weight proteins and are therefore inherently immunogenic, and the generation of anti-drug antibodies is related to treatment failure or the development of adverse events [25].

Two recent systematic reviews revealed that the proportion of RA patients who develop treatment-induced anti-drug antibodies varies: the incidence is the highest in those treated with IFX (0-83\%), followed by those treated with ADA (0-54\%), CZP (3$25 \%)$, GLM (0-19\%), and ETA (0-13\%) [13, 26]. The antibodies may appear as early as during the first months of exposure (in up to $44 \%$ of RA patients treated with IFX and in $19 \%$ of those treated with ADA) $[17,18]$. Their frequency depends on not only the type of TNF inhibitor but also the measurement method used. Moots, et al. [21] have recently investigated the occurrence of anti-ETA, anti-ADA, and anti-IFX antibodies in a relatively large, multinational, cross-sectional real-world population of RA patients on stable treatment for 6-24 months, and found that none of the patients treated with ETA had detectable antibodies, whereas $24.4 \%$ of those in the pooled ADA/IFX group did, indicating the greater immunogenicity of ADA and IFX. Interestingly, almost all patients concomitantly treated with MTX developed antibodies, the rate of which may increase over time. The risk factors for developing anti-ADA/IFX antibodies in one cohort of RA patients-most of whom were naive to antiTNF treatment and were co-treated with MTX-were a longer disease duration, higher baseline DAS28 values, and lifetime smoking (which may be associated not only with the development of anti-citrullinated protein antibodies but also with overall B-cell responses) [27]. Magill, et al. [28] have recently shown the direct involvement of memory B cells in anti-drug antibody formation; they found that a reduced level of signal regulatory protein $\alpha / \beta$ (SIRP $\alpha / \beta$ )-positive memory B cells before ADA treatment predicts the development of anti-ADA antibodies after 12 months of follow-up. However, whether this is exclusively a biomarker of response or biologically related to anti-ADA antibody development is still unknown. Bartelds, et al. [29] observed that RA patients previously treated with IFX who switched to ADA after developing anti-IFX antibodies seemed to develop anti-ADA antibodies more frequently than switchers without anti-IFX antibodies, and the highest rates of response to ADA were observed mostly in switchers without anti-IFX antibodies. These findings 


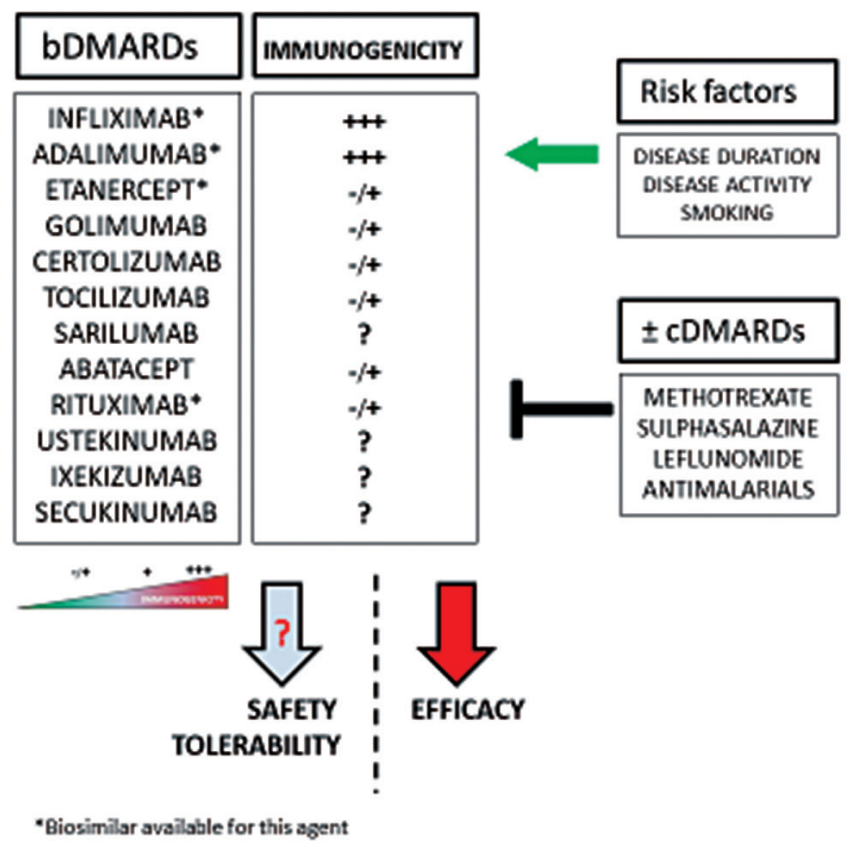

Fig. 1. Biological disease-modifying anti-rheumatic drugs (bDMARDs) are associated with immunogenicity, leading to the development of anti-drug antibodies that affect drug efficacy and may affect drug safety and tolerability. The development of anti-drug antibodies seems to be influenced by multiple risk factors and may be modulated by the concomitant use of conventional synthetic DMARDs (cs-DMARDs).

suggested that patients who develop antibodies against a first bDMARD are more likely to develop antibodies against a second [29] (Fig. 1).

Anti-ADA, anti-CZP, and anti-GLM antibodies act by targeting idiotypes close to the epitope-binding portions of the Fab regions of the mAbs, thus preventing their binding to TNF and finally reducing the effects of the drugs. Moreover, the complex formed by an anti-TNF drug and its specific antibody may affect its pharmacokinetics by increasing its clearance and lowering its serum level, thus having a potentially negative impact on clinical responses. A recently reported randomized controlled trial (RCT) and real-life data showed that anti-drug antibody-positive patients treated with ADA, IFX, CZP, or GLM had lower serum bDMARD levels than those who are anti-drug antibody-negative [21, 30-33]. However, although one study found that serum IFX levels were low $(<0.5 \mu \mathrm{g} / \mathrm{mL})$ in one-quarter of RA patients, no more than $11 \%$ had detectable anti-IFX antibodies, suggesting that additional factors may be responsible for the reduced efficacy of IFX [34].

Anti-drug antibody-positive RA patients treated with anti-TNF bDMARDs have higher inflammation marker levels and greater disease activity, show less improvement in disease activity, and are less likely to achieve a clinical response even in the earliest phases of treatment [16, 18, 21, 35]. A meta-analysis of 12 prospective cohort observational studies revealed that the presence of anti-drug antibodies reduces the rate of clinical responses to ADA or IFX by $68 \%$, an effect that was attenuated by the concomitant use of MTX [8], which is associated with a dose-dependent reduction in the immunogenicity of anti-TNF agents, including non-chimeric agents, such as ADA [32, 36]. These data have been confirmed in a recent meta-analysis of 68 studies (38 RCTs and 30 observational studies) [37]. Finally, a meta-analysis of 10 studies involving 1,806 RA patients revealed that anti-drug antibody positivity was significantly associated with a reduced clinical response at all follow-up time points [38]. Antibodies against anti-TNF drugs are associated with the safety and tolerability of mainly IFX as they are related to infusion-site or other adverse drug reactions [39-41].

In conclusion, the development of anti-drug antibodies in RA patients is probably frequent and related to the molecular structure, dose, and administration regimen of the bDMARDs involved, the concomitant use of MTX, and individual autoimmunity profiles (i.e., the presence of B-cell subsets), which affect not only treatment response rate but also drug safety and tolerability.

\section{IMMUNOGENICITY OF OTHER BIOLOGICAL AGENTS}

Other agents used in the management of inflammatory diseases include abatecept (ABA, a T-cell activation inhibitor/costimulation modulator), rituximab (an anti-CD20 mAb), tocilizumab [an interleukin-6 receptor (IL-6R) antagonist], secukinumab (an IL17A antagonist), and ustekinumab (an IL-12/23 blocker), all of which have unique protein structures and induce different immune responses. The immunogenicity of $\mathrm{ABA}$ has been evaluated in 10 studies; eight of these were in patients with RA and two in patients with juvenile rheumatoid arthritis (JRA). Of the first eight studies, two lasted less than 24 weeks, and six more than 24 weeks. Of the 10 studies, six assessed immunogenicity using an ELISA and four used an electrochemiluminescent $(E C L)$ immunoassay. The receptor fusion protein ABA show immunogenicity to the linker between the soluble receptor and the Fc portion, which may partially explain the low incidence of antidrug antibodies (2-20\% in RA patients and $2-11 \%$ in JRA patients) and the absence of neutralizing activity [26, 42, 43]. The immunogenicity of rituximab has been evaluated in 12 studies, 
seven of which lasted less than 24 weeks, and five more than 24 weeks. ELISA was used in six studies and ECL immunoassay in four, while two used unknown methods. The frequency of anti-drug antibodies was 0-21\% in RA patients [26, 44-47].

The immunogenicity of tocilizumab has been evaluated in 22 studies, eight of which lasted less than 24 weeks, and 14 more than 24 weeks, and all of which used ELISA. The frequency of anti-drug antibodies was $0-16 \%$ in RA patients and $1-8 \%$ in JRA patients, a low incidence that may be partially explained by the fact that IL-6 is necessary for an antibody response or the poor sensitivity of the assay in the presence of circulating drug levels [26, 44-46].

The immunogenicity of secukinumab has been evaluated in 11 studies; two involving patients with SpA, two involving patients with PsA, and seven involving patients with psoriasis. Of these, four studies lasted less than 24 weeks, and seven more than 24 weeks; six studies used ELISA, five used an ECL immunoassay. The frequency of anti-drug antibodies was $0-0.3 \%$ in SpA patients, $0-0.1 \%$ in PsA patients, and $0-1 \%$ in psoriasis patients [26, 44-48].

The immunogenicity of ustekinumab has been evaluated in 15 studies; 11 involving patients with psoriasis, two involving patients with Crohn's disease (CD), and two involving patients with PsA. Among these, 12 studies lasted more than 24 weeks, three less than 24 weeks. Six studies used ELISA, five an ECL immunoassay, and four RIA. The frequency of anti-drug antibodies was $0-1 \%$ in patients with $C D, 8-11 \%$ in those with PsA, and 4-8.6\% in those with psoriasis [26, 44-49].

\section{IMMUNOGENICITY OF BIOSIMILARS}

A biosimilar is a biological product approved on the basis of the totality of evidence demonstrating that it is highly similar to an approved biological RP in terms of its physicochemical and biological properties, clinical efficacy, and safety [50]. CT-P13 (Remsima ${ }^{\circledR}$; Inflectra ${ }^{\circledR}$ ) was the first biosimilar of INF-RP Reference Product (Remicade ${ }^{\circledR}$ ) to be approved by the European Medicines Agency (EMA) and the FDA. In the pivotal randomized controlled trials that led to its approval (PLANETAS and PLANETRA), anti-drug and neutralizing antibodies (NAbs) were assessed using ECL and automated Gyros ${ }^{\mathrm{TM}}$ immunoassays, respectively. Anti-drug antibodies were detected at a higher rate in RA patients than in patients with AS, but these proportions were comparable in those treated with CT-P13 and those treated with the RP; furthermore, the antibodies persisted throughout the study period in $80-90 \%$ of the patients in whom they were de- tected $[51,52]$. Thirteen studies on CT-P13 have been published to date (seven on RA, four on SpA, and two on $\mathrm{CD}$ ), and anti-drug antibodies have been detected in $26-52 \%$ of RA patients, $27 \%$ of SpA patients, $24 \%$ of ulcerative colitis (UC) patients, and $21 \%$ of $C D$ patients. Twelve studies lasted more than 24 weeks; three used ELISA and nine an ECL immunoassay. One recent study demonstrated that antibodies against CT-P13 recognize and bind the RP, and vice versa, indicating that the two drugs share immunodominant epitopes. The findings of this study are consistent with the previously reported close biosimilarity between CT-P13 and the RP and suggest that marketed kits for detecting anti-drug antibodies against infliximab can be used to detect both [53].

Overall rates of anti-drug antibody positivity and consequent immunogenicity were similar in the recipients of SB2, another biosimilar of INF-RP (Remicade ${ }^{\circledR}$ ), and those receiving IFX-RP (62.4\% vs $57.5 \%$ by week 54 ) [54]. During the switching period, immunogenicity remained similar between the two treatment groups. Of the patients who were anti-drug antibody-negative up to week 54, antibodies developed in $14.6 \%$ of those who switched from the RP to SB2, $14.9 \%$ of those who remained on the RP, and $14.1 \%$ of those of who remained on SB2 [54]. Data on SB4, a biosimilar of etanercept RP $\left(\right.$ Enbrel $\left.{ }^{\circledR}\right)$, were published in a 52-week study of patients with RA [55]. The anti-drug antibody detection rate was significantly lower in the SB4 group than in the etanercept RP group during the first 24 weeks of treatment $(0.7 \%$ vs $13.1 \%$ of patients; $P<0.001)$ [55] and at the end of the 52 -week study $(1.0 \%$ vs $13.1 \%$ of patients; $P<0.001$ ) [56]. However, the EMA identified confounding factors that may have introduced a bias towards SB4 and declared that it was premature to conclude that SB4 is less immunogenic than the RP [57]. The overall incidence of antidrug antibodies after week 52 was $0.8 \%$ in the SB4/SB4 group and $0.9 \%$ in the RP/SB4 group [58]. Only one patient in the RP group developed NAbs.

GP2015, a biosimilar of ADA, has been tested for immunogenicity only in the dermatological EGALITY trial [59]. Anti-drug antibodies (all low-titer and non-neutralizing) were detected in six patients, including five etanercept RP recipients (1.9\%) who tested positive during the first four weeks of the 24-week treatment period, but negative at subsequent time points. The incidence of anti-drug antibodies against CT-P10, a biosimilar of rituximab, and the rituximab RP is similar. In a phase 1 trial involving RA patients, $17.6 \%$ of the recipients of either had detectable anti-drug antibodies by week 24 after one course of treatment. Anti-drug antibodies were detected in $5.1 \%$ of CTP10 
and $3.2 \%$ of rituximab RP recipients over a period of 12 weeks [60, 61]. In another study of RA patients [62], binding anti-drug antibodies developed in 16.5\% of patients receiving GP2013, another biosimilar of rituximab, and in $15.1 \%$ of rituximab RP recipients [62], but $7.1 \%$ and $9.6 \%$, respectively, of the cases were transient. Nabs were detected in 3.9\% of the GP2013 recipients and $0.6 \%$ of the RP recipients.

\section{THERAPEUTIC MONITORING OF BIOLOGICAL AGENTS: THE ROLE OF THE LABORATORY}

Biological agents, especially TNF inhibitors, have been a major support in the management of rheumatic diseases, but most of the therapeutic proteins induce a complex immune response and the formation of antibodies, which lead to loss of efficacy by eliminating the pharmacological action of the drug or altering its pharmacokinetics. Therefore, it is very important to use sensitive, specific, and validated methods for assessing immunological responses. Therapeutic drug monitoring (TDM) has emerged as an effective means to optimize treatment to maximize its benefits. TDM can inform medical decisions in the case of primary failure or secondary loss of response and should also be considered periodically in patients in clinical remission or those for whom a drug holiday is contemplated. Drug and anti-drug antibodies monitoring can help clinicians to understand the cause(s) of treatment failure, a sub-optimal response, infusion reactions, or secondary failure $[6,13,17,63]$. Screening assays should be sensitive, specific, and capable of detecting all isotypes of antibodies against a given biological drug and the available analytical assays include ELISA, RIA and new platforms, such as ECL and the automated Gyros technology [13, 51, 52, $64,65]$. However, the detection and measurement of antidrug antibodies is complex, and the results can be affected by the assay used. Bridging ELISA with the antigen immobilized on the plate is a simple approach that is acceptably sensitive, but it is also associated with a very high false positivity rate, and antidrug antibodies measurement can be confounded by the presence of rheumatoid factor and anti-hinge antibodies [13, 66].

Interference by the circulating drug is another major challenge for immunogenicity assays because it may lead to falsenegative results as the current antibody assays only measure unbound antibodies and not those bound in immune complexes. Therefore, when interpreting antibody assessment results, the drug dose, timing of administration, and serum drug level should be considered [67]. To minimize interference in anti-drug antibody assays, blood samples should be collected immediately before the next administration, when drug levels are at their lowest [68]. New technologies allow the identification of specific isotypes of anti-drug antibodies with excellent sensitivity, allowing smaller sample volumes, minimizing the use of critical reagents, and saving time, while limiting the cost of consumables [69]. However, the short incubation time for neutralization and bridging reactions may not be sufficient if low-affinity antibodies are present in the sample.

Repeated testing is useful to determine whether the antibodies are transient or persistent and may also be appropriate for patients who respond to treatment, but initially have low antibody titers. Confirmatory assays are necessary to eliminate false-positive results and a common approach is to add an excess of antigen to the sample, which should reduce the positive signal of truly positive samples [70]. The determination of NAbs is an important part of an immunogenicity assessment and is usually done using cell-based and non-cell-based assays [71]. Given the difficulty in detecting anti-drug antibodies and determining the relationship between serum levels of biological drugs and the development of immunogenicity, it seems that testing trough serum drug levels may not only allow personalized drug dosing but it could also be cost-effective [72]. In the case of a lack or loss of efficacy of a biological agent, the drug level can provide important information: in the case of a low trough serum level, an insufficient dose or immunization against the drug should be considered. If the serum drug level is sufficient, it is likely that the choice of the target is not appropriate and switching to another biological drug class should be considered.

Various analytic techniques are used to measure the levels of anti-TNF drugs, such as ELISAs, RIAs, functional cell-based reporter gene assays, and homogeneous mobility shift assays. However, there is no single gold standard technique and, although drug levels measured using different assays may correlate with each other and lead to the same clinical decision, there are some systematic differences [73-83]. A recent meta-analysis revealed that $20-30 \%$ of test results are likely to be incorrect because different tests use different cut-off values, suggesting that more clinical trial evidence from test-based studies is needed to optimize their use in clinical practice [84]. To improve therapeutic decision making, the same assay should be used during follow-up of a patient [85]. Finally, commercially available IFX ELISAs can also be used to quantify biosimilars without the need for any adjustment $[86,87]$. As most of the ELISAs used for TDM require the analysis of multiple samples simultaneously, it takes at least one or two weeks before the results become clinically available in a cost-effective manner. Further- 
Table 3. Summary of useful antibody-detecting assays

\begin{tabular}{|c|c|c|}
\hline Assay & Advantages & Disadvantages \\
\hline ELISA & $\begin{array}{l}\text { Simple, with acceptable sensitivity; reagents readily } \\
\text { available }\end{array}$ & $\begin{array}{l}\text { Anti-drug antibody measurements may be confounded by the presence of rheumatoid factor and } \\
\text { anti-hinge antibodies, and high levels of circulating drug (the presence of the drug may lead to } \\
\text { false negative results as the current assays measure unbound antibodies, not those bound in an } \\
\text { immune complex) }\end{array}$ \\
\hline RIA & Good sensitivity; ready-to-use reagents; limited costs & May be influenced by high levels of circulating drug; occupational exposure to radioactive materials \\
\hline ECL assay & Highly sensitive: minimal influence of sample matrix & Requires an ECL instrument; reagents may be expensive \\
\hline Gyros & $\begin{array}{l}\text { Excellent sensitivity; reduced drug interference; } \\
\text { low-volume samples; minimal use of critical } \\
\text { reagents; time saving }\end{array}$ & $\begin{array}{l}\text { High costs of reagents and consumables; the short incubation time for a neutralization and } \\
\text { bridging reaction may not be sufficient if sample contains low affinity antibodies }\end{array}$ \\
\hline
\end{tabular}

Abbreviations: ELISA, enzyme linked immunosorbent assay; RIA, radioimmuno assay; ECL electrochemiluminescence.

more, as blood samples are collected immediately before an infusion, TDM results become available only at the time of the next scheduled infusion. In an attempt to overcome this drawback, some rapid tests for measuring serum IFX levels have been introduced and quantitatively and qualitatively validated in comparison with conventional ELISAs. These point-of-care tests may be advantageous in the case of non-responding patients as they allow low IFX levels to be detected by a nurse, physician, or researcher during the course of a single outpatient visit, which means that the treatment can be adjusted immediately rather than at the subsequent infusion, which is usually six to eight weeks later [88-90] (Table 3).

The real prevalence of anti-drug antibodies is still unknown because differences in the specificity and sensitivity of the available assays make it very difficult to compare studies and has led to considerable variability in the published figures [91, 92]. However, numerous attempts have been made in the areas of standardization and harmonization, such as the production of high-quality internal quality controls to validate routine drug and anti-drug antibody assays and to reduce intra laboratory variability, and external quality control to reduce interlaboratory variability. Moreover, it is expected that biosimilars will become a significant growth driver for the pharmaceutical industry, mainly because of the current market penetration of biological agents and the need to save costs in comparison with original drugs. Nevertheless, studies validating immunogenicity assays are urgently needed to support the further development of biosimilars.

\section{CONCLUSIONS}

This review aimed to highlight the role of laboratories in ensuring appropriate use of biological drugs, which have become increasingly important in the treatment of diseases ranging from rheumatic diseases and other chronic conditions involving various organs and systems to various types of cancer. We focused on rheumatic diseases because they represent one of the main targets of biological drugs, which are often used in combination with csDMARDs. Biological treatment is quite safe, at least in the short to medium term, but some unwanted effects are possible. A reduced immune response may lead to the onset of infections which although generally not serious, may become severe in patients with latent infections; injection-site cutaneous reactions or a vasomotor crisis may occur during intravenous infusion; and autoantibodies associated with manifestations typical of an autoimmune disease may appear.

Unlike synthetic pharmacological molecules, biological drugs are produced in cells, and their production requires such precise procedures that even a small change in any part of the process can significantly alter the molecular structure and consequently, drug efficacy and safety. Therefore, the production and distribution of biological drugs needs to be carefully controlled, bearing in mind that difficulties inherent to the production techniques increase with the complexity of the molecule. Further, as they are proteins (and as such, immunogens), they may be recognized as non-self and thus induce an immune reaction that neutralizes their effectiveness or even have more serious consequences. Many factors can influence the risk of immunogenicity: the quality of the biological drug (e.g., the possible presence of contaminants arising from the production process that may interfere with drug activity), the characteristics of the production process, the duration of treatment, the site of drug administration, and patient characteristics (e.g., the condition of the immune system, genetic profile).

Biological drugs can interfere with cytokines. Chronic inflammatory diseases are characterized by an imbalance in favor of inflammatory over anti-inflammatory cytokines, and biological 
drugs act by blocking the activity of the former, which are produced in large quantities by patients with RA or other chronic inflammatory diseases [93, 94].

Many biological drugs are currently on the market, and their different mechanisms of action and possible drug-related events may affect their tolerability, efficacy, and safety due to their differential immunomodulatory action. This is where clinical laboratories play a pivotal role.

\section{Endorsements}

This paper is endorsed by the World Association of Societies of Pathology and Laboratory Medicine - WASPaLM and the Società Italiana di Patologia Clinica e Medicina di Laboratorio - SIPMeL.

\section{Conflicts of Interest}

None declared.

\section{ORCID}

$\begin{array}{ll}\text { Maurizio Benucci } & \text { https://orcid.org/0000-0001-8180-6660 } \\ \text { Valentina Grossi } & \text { https://orcid.org/0000-0001-6327-0874 } \\ \text { Mariangela Manfredi } & \text { https://orcid.org/0000-0001-9242-2793 } \\ \text { Arianna Damiani } & \text { https://orcid.org/0000-0003-2817-4822 } \\ \text { Maria Infantino } & \text { https://orcid.org/0000-0002-6200-4467 } \\ \text { Paolo Moscato } & \text { https://orcid.org/0000-0002-8980-5141 } \\ \text { Luigi Cinquanta } & \text { https://orcid.org/0000-0002-2287-3027 } \\ \text { Elisa Gremese } & \text { https://orcid.org/0000-0002-2248-1058 } \\ \text { Barbara Tolusso } & \text { https://orcid.org/0000-0002-9108-6609 } \\ \text { Luca Petricca } & \text { https://orcid.org/0000-0003-3544-3162 } \\ \text { Anna Laura Fedele } & \text { https://orcid.org/0000-0001-9148-1548 } \\ \text { Stefano Alivernini } & \text { https://orcid.org/0000-0002-7383-4212 } \\ \text { Fabiola Atzeni } & \text { https://orcid.org/0000-0002-9328-3075 } \\ \text { Giovanni Minisola } & \text { https://orcid.org/0000-0003-4702-7094 } \\ \text { Roberto Verna } & \text { https://orcid.org/0000-0002-1869-3912 }\end{array}$

\section{REFERENCES}

1. World Health Organization. International nonproprietary names (INN) for biological and biotechnological substances. http://www.webcitation. org/6rGAZvnd2 (Updated 2018).

2. Scott DL. Biologics-based therapy for the treatment of rheumatoid arthritis. Clin Pharmacol Ther 2012;91:30-43.

3. U.S. Food and Drug Administration. Guidance for industry: scientific considerations in demonstrating biosimilarity to a reference productdraft guidance. United States Food and Drug Administration. http://
www.fda.gov/downloads/Drugs/GuidanceComplianceRegulatoryInformation/Guidances/UCM291128.pdf (Updated on Jun 2019).

4. Isaacs J, Gonçalves J, Strohal R, Castañeda-Hernández G, Azevedo V, Dörner T, et al. The biosimilar approval process: how different is it? Considerations Med 2017;1:3-6.

5. Takeuchi T, Miyasaka N, Inoue K, Abe T, Koike T. Impact of trough serum level on radiographic and clinical response to infliximab plus methotrexate in patients with rheumatoid arthritis: results from the RISING study. Mod Rheumatol 2009;19:478-87.

6. Svenson M, Geborek P, Saxne T, Bendtzen K. Monitoring patients treated with anti-TNF- $\alpha$ biopharmaceuticals: assessing serum infliximab and anti-infliximab antibodies. Rheumatology (Oxford) 2007;46:1828-34.

7. St. Clair E, Wagner C, Fasanmade A, Wang B, Schaible T, Kavanaugh A, et al. The relationship of serum infliximab concentrations to clinical improvement in rheumatoid arthritis results from ATTRACT, a multicenter, randomized, double-blind, placebo-controlled trial. Arthritis Rheum 2002;46;1451-9.

8. Garcês S, Demengeot J, Benito-Garcia E. The immunogenicity of antiTNF therapy in immune-mediated inflammatory diseases: a systematic review of the literature with a meta-analysis. Ann Rheum Dis 2013;72: 1947-55.

9. Maneiro JR, Salgado E, Gomez-Reino JJ. Immunogenicity of monoclonal antibodies against tumor necrosis factor used in chronic immunemediated inflammatory conditions: systematic review and meta-analysis. JAMA Intern Med 2013;173:1416-28.

10. Smolen JS, Landewe R, Breedveld FC, Buch M, Burmester G, Dougados $\mathrm{M}$, et al. EULAR recommendations for the management of rheumatoid arthritis with synthetic and biological disease-modifying antirheumatic drugs: 2013 update. Ann Rheum Dis 2014;73:492-509.

11. Hart MH, de Vrieze H, Wouters D, Wolbink GJ, Killestein J, de Groot ER, et al. Differential effect of drug interference in immunogenicity assays. J Immunol Methods 2011;372:196-203.

12. Jani M, Chinoy H, Warren R, Griffiths C, Plant D, Fu B, et al. Clinical utility of random anti-tumor necrosis factor drug-level testing and measurement of antidrug antibodies on the long-term treatment response in rheumatoid arthritis. Arthritis Rheum 2015;67:2011-9.

13. Vincent FB, Morand EF, Murphy K, Mackay F, Mariette X, Marcelli C. Antidrug antibodies (ADAb) to tumour necrosis factor (TNF)-specific neutralising agents in chronic inflammatory diseases: a real issue, a clinical perspective. Ann Rheum Dis 2013;72:165-78.

14. Smith HW, Butterfield A, Sun D. Detection of antibodies against therapeutic proteins in the presence of residual therapeutic protein using a solid-phase extraction with acid dissociation (SPEAD) sample treatment prior to ELISA. Regul Toxicol Pharmacol 2007;49:230-7.

15. Llinares-Tello, Rosas-Gómez de Salazar J, Senabre-Gallego JM, SantosSoler G, Santos-Ramírez C, Salas-Heredia E, et al. Practical application of acid dissociation in monitoring patients treated with adalimumab. Rheumatol Int 2014;34:1701-8.

16. Radstake TR, Svenson M, Eijsbouts AM, van den Hoogen FH, Enevold C, van Riel PL, et al. Formation of antibodies against infliximab and adalimumab strongly correlates with functional drug levels and clinical responses in rheumatoid arthritis. Ann Rheum Dis 2009;68:1739-45.

17. Bendtzen K, Geborek P, Svenson M, Larsson L, Kapetanovic MC, Saxne T. Individualized monitoring of drug bioavailability and immunogenicity in rheumatoid arthritis patients treated with the tumor necrosis factor alpha inhibitor infliximab. Arthritis Rheum 2006;54:3782-9.

18. Bartelds GM, Krieckaert CL, Nurmohamed MT, van Schouwenburg PA, Lems WF, Twisk JW, et al. Development of antidrug antibodies against adalimumab and association with disease activity and treatment failure during long-term follow-up. JAMA 2011;305:1460-8. 
19. Dore RK, Mathews S, Schechtman J, Surbeck W, Mandel D, Patel A, et al. The immunogenicity, safety, and efficacy of etanercept liquid administered once weekly inpatients with rheumatoid arthritis. Clin Exp Rheumatol 2007;25:40-6.

20. de Vries MK, van der Horst-Bruinsma IE, Nurmohamed MT, Aarden LA, Stapel SO, Peters MJ, et al. Immunogenicity does not influence treatment with etanercept in patients with ankylosing spondylitis. Ann Rheum Dis 2009;68:531-5.

21. Moots RJ, Xavier RM, Mok CC, Rahman MU, Tsai WC, Al-Maini MH, et al. The impact of anti-drug antibodies on drug concentrations and clinical outcomes in rheumatoid arthritis patients treated with adalimumab, etanercept, or infliximab: results from a multinational, real-world clinical practice, non-interventional study. PLoS One 2017;12:e0175207.

22. Conti F, Ceccarelli F, Massaro L, Cipriano E, Di Franco M, Alessandri C, et al. Biological therapies in rheumatic diseases. Clin Ter 2013;164: e413-428.

23. Schaeverbeke T, Truchetet ME, Kostine M, Barnetche T, Bannwarth B, Richez C. Immunogenicity of biologic agents in rheumatoid arthritis patients: lessons for clinical practice. Rheumatology (Oxford) 2016;55: 210-20.

24. Tracey D, Klareskog L, Sasso EH, Salfeld JG, Tak PP. Tumor necrosis factor antagonist mechanisms of action: a comprehensive review. Pharmacol Ther 2008;117:244-79.

25. Matucci A, Cammelli D, Cantini F, Goletti D, Marino V, Milano GM, et al. Influence of anti-TNF immunogenicity on safety in rheumatic disease: a narrative review. Expert Opin Drug Saf 2016;15:3-10.

26. Strand V, Balsa A, Al-Saleh J, Barile-Fabris L, Horiuchi T, Takeuchi T, et al. Immunogenicity of biologics in chronic inflammatory diseases: a systematic review. BioDrugs 2017;31:299-316.

27. Quistrebert J, Hässler S, Bachelet D, Mbogning C, Musters A, Tak PP, et al. Incidence and risk factors for adalimumab and infliximab antidrug antibodies in rheumatoid arthritis: a European retrospective multicohort analysis. Semin Arthritis Rheum 2019;48:967-75.

28. Magill L, Adriani M, Berthou V, Chen K, Gleizes A, Hacein-Bey-Abina S, et al. Low percentage of signal regulatory protein $\alpha / \beta+$ memory $B$ cells in blood predicts development of anti-drug antibodies (ADA) in adalimumab-treated rheumatoid arthritis patients. Front Immunol 2018;9:2865.

29. Bartelds S, Wijbrandts CA, Nurmohamed MT, Stapel S, Lems WF, Aarden $L$, et al. Anti-infliximab and anti-adalimumab antibodies in relation to response to adalimumab in infliximab switchers and anti-tumor necrosis factor naive patients: a cohort study. Ann Rheum Dis 2010;69:817-21.

30. Chen DY, Chen YM, Tsai WC, Tseng JC, Chen YH, Hsieh CW, et al. Significant associations of antidrug antibody levels with serum drug trough levels and therapeutic response of adalimumab and etanercept treatment in rheumatoid arthritis. Ann Rheum Dis 2015;74:e16.

31. Jani M, Chinoy H, Warren RB, Fu B, Griffiths CE, Morgan AW, et al. SAT0052 Influence of immunogencity and drug levels on the efficacy of long-term treatment of rheumatoid arthritis with adalimumab and etanercept: a UK-based prospective study. Ann Rheum Dis 2014;73:608.

32. Eng G, Fana V, Omerovic E, Højsgaard P, Lindegaard HM, Jensen EK, et al. Presence of antibodies to adalimumab and infliximab in patients with rheumatoid arthritis in clinical remission. Ann Rheum Dis 2013; 72:230

33. Docourau E, Mulleman D, Paintaud G, Miow Lin DC, Lauféron F, Ternant $D$, et al. Antibodies toward infliximab are associated with low infliximab concentration at treatment initiation and poor infliximab maintenance in rheumatoid disease. Arthitis Res Ther 2011;13:R105.

34. Siljehult F, Arlestig L, Eriksson C, Rantapää-Dahlqvist S. Concentration of infliximab and anti-drug antibodies in relation to clinical response in patients with rheumatoid arthritis. Scand J Rheumatol 2018;47:345-50.
35. Chen DY, Chen YM, Hung WT, Chen HH, Hsieh CW, Chen YH, et al. Immunogenicity, drug trough levels and therapeutic response in patients with rheumatoid arthritis and ankyloses spondyloarthritis after 24week golimumab treatment. Ann Rheum Dis 2015;74:2261-4.

36. Krieckaert CL, Nurmohamed MT, Wolbink GJ. Methotrexate reduces immunogenicity in adalimumab treated rheumatoid arthritis patients in a dose dependent manner. Ann Rheum Dis 2012;71:1914-5.

37. Thomas SS, Borazan N, Barroso N, Duan L, Taroumian S, Kretzmann B, et al. Comparative immunogenicity of TNF Inhibitors: impact on clinical efficacy and tolerability in the management of autoimmune diseases. A systematic review and meta-analysis. BioDrugs 2015;29:241-58.

38. Wu C, Wang S, Xian P, Yang L, Chen Y, Mo X, et al. Effect of anti-TNF antibodies on clinical response in rheumatoid arthritis patients: a metaanalysis. BioMed Res Int 2016;2016:7185708.

39. Krintel SB, Grunert VP, Hetland ML, Johansen JS, Rothfuss M, Palermo $G$, et al. The frequency of anti-infliximab antibodies in patients with rheumatoid arthritis treated in routine care and the association with adverse drug reaction and treatment failure. Rheumatology (Oxford) 2013;52: 1245-53.

40. Hoxha A, Calligaro A, Tonello M, Ramonda R, Carletto A, Paolazzi G, et al. The clinical relevance of early anti-adalimumab antibodies detection in rheumatoid arthritis, ankylosing spondylitis and psoriatic arthritis: a prospective multicentre study. Joint Bone Spine Rev Rheum 2016;83: 167-71.

41. Pascual-Salcedo D, Plasencia C, Ramiro S, Nuño L, Bonilla G, Nagore D, et al. Influence of immunogenicity on the efficacy of long-term treatment with infliximab in rheumatoid arthritis. Rheumatology 2011;50: 1445-52.

42. Genovese MC, Pacheco-Tena C, Covarrubias A, Leon G, Mysler E, Keiserman $\mathrm{M}$, et al. Longterm safety and efficacy of subcutaneous abatacept in patients with rheumatoid arthritis: 5-year results from a phase IIIb trial. J Rheumatol 2018;45:1085-92.

43. Brunner HI, Tzaribachev N, Vega-Cornejo G, Louw I, Berman A, Calvo Penadés I, et al. Paediatric Rheumatology International Trials Organisation (PRINTO) and the Pediatric Rheumatology Collaborative Study Group (PRCSG). Subcutaneous abatacept in patients with polyarticularcourse juvenile idiopathic arthritis: results from a phase III open-label study. Arthritis Rheumatol 2018;70:1144-54.

44. Burmester GR, Choy E, Kivitz A, Ogata A, Bao M, Nomura A, et al. Low immunogenicity of tocilizumab in patients with rheumatoid arthritis. Ann Rheum Dis 2017;76:1078085.

45. Benucci M, Meacci F, Grossi V, Infantino M, Manfredi M, Bellio E, et al. Correlations between immunogenicity, drug levels, and disease activity in an Italian cohort of rheumatoid arthritis patients treated with tocilizumab. Biologics 2016;10:53-8.

46. Sigaux J, Hamze M, Daien C, Morel J, Krzysiek R, Pallardy M, et al. Immunogenicity of tocilizumab in patients with rheumatoid arthritis. Joint Bone Spine 2017;84:39-45.

47. Mok CC. Rituximab for the treatment of rheumatoid arthritis: an update. Drug Des Devel Ther 2013;8:87-100.

48. Karle A, Spindeldreher S, Kolbinger F. Secukinumab, a novel anti-IL$17 \mathrm{~A}$ antibody, shows low immunogenicity potential in human in vitro assays comparable to other marketed biotherapeutics with low clinical immunogenicity. MAbs 2016;8:536-50.

49. Verstockt B, Deleenheer B, Van Assche G, Vermeire S, Ferrante M. A safety assessment of biological therapies targeting the IL-23/IL-17 axis in inflammatory bowel diseases. Expert Opin Drug Saf 2017;16:809-21.

50. European Medicines Agency. Guideline on similar biological medicinal products (Revision). CHMP/437/04 Rev 1. London, UK: 2014;1-7.

51. Park W, Hrycaj P, Jeka S, Kovalenko V, Lysenko G, Miranda P, et al. A 
randomised, double-blind, multicentre, parallel-group, prospective study comparing the pharmacokinetics, safety, and efficacy of CT-P13 and innovator infliximab in patients with ankylosing spondylitis: the PLANETAS study. Ann Rheum Dis 2013;72:1605-12.

52. Yoo DH, Hrycaj P, Miranda P, Ramiterre E, Piotrowski M, Shevchuk S, et al. A randomised, double-blind, parallel-group study to demonstrate equivalence in efficacy and safety of CT-P13 compared with innovator infliximab when coadministered with methotrexate in patients with active rheumatoid arthritis: the PLANETRA study. Ann Rheum Dis 2013; 72:1613-20.

53. Reinisch W, Jahnsen J, Schreiber S, Danese S, Panés J, Balsa A, et al. Evaluation of the cross-reactivity of antidrug antibodies to CT-P13 and infliximab reference product (Remicade): an analysis using immunoassays tagged with both agents. BioDrugs 2017;31:223-37.

54. Lamb YN, Scott LJ, Deeks ED. SB2: an infliximab biosimilar. BioDrugs 2017;31:461-4.

55. Emery P, Vencovský J, Sylwestrzak A, Leszczyński P, Porawska W, Baranauskaite $A$, et al. A phase III randomised, double-blind, parallel-group study comparing SB4 with etanercept reference product in patients with active rheumatoid arthritis despite methotrexate therapy. Ann Rheum Dis 2017;76:51-7.

56. Emery P, Vencovský J, Sylwestrzak A, Leszczyński P, Porawska W, Stasiuk $B$, et al. Long-term efficacy and safety in patients with rheumatoid arthritis continuing on SB4 or switching from reference etanercept to SB4. Ann Rheum Dis 2017; 211591.

57. European Medicines Agency. European public assessment report (EPAR): Benepali (etanercept) 2016. http://www.ema.europa.eu.

58. Emery P, Vencovský J, Sylwestrzak A, Leszczynski P, Porawska W, Baranauskaite $A$, et al. 52-week results of the phase 3 randomized study comparing SB4 with reference etanercept in patients with active rheumatoid arthritis. Rheumatology (Oxford) 2017;56:2093-101.

59. Poetzl J, Arlt I, von Richter O, Wöhling H, Afonso M, Schaffar G. Stateof-the-art immunogenicity evaluation in phase 3 confirmatory study (EGALITY) with etanercept biosimilar GP2015. J Eur Acad Dermatol Venereol 2018;32:e130-2.

60. Yoo DH, Suh CH, Shim SC, Jeka S, Cons-Molina FF, Hrycaj P, et al. A multicentre randomised controlled trial to compare the pharmacokinetics, efficacy and safety of CT-P10 and innovator rituximab in patients with rheumatoid arthritis. Ann Rheum Dis 2017;76:566-70.

61. Coiffier B, Sancho JM, Jurczak W, Jin Seok Kim, Raj V Nagarkar, Edvard Zhavrid, et al. Pharmacokinetic and safety of CT-P10, a biosimilar candidate to the rituximab reference product, in patients with newly diagnosed advanced stage follicular lymphoma (AFL). Blood 2016;128: 1807.

62. Smolen JS, Cohen SB, Tony HP, Scheinberg M, Kivitz A, Balanescu A, et al. A randomised, double-blind trial to demonstrate bioequivalence of GP2013 and reference rituximab combined with methotrexate in patients with active rheumatoid arthritis. Ann Rheum Dis 2017;76:1598602.

63. Garcês S, Antunes M, Benito-Garcia E, da Silva JC, Aarden L, Demengeot J, et al. A preliminary algorithm introducing immunogenicity assessment in the management of patients with RA receiving tumour necrosis factor inhibitor therapies. Ann Rheum Dis 2014;73:1138-43.

64. Park W, Yoo DH, Jaworski J, Brzezicki J, Gnylorybov A, Kadinov V, et al. Comparable long-term efficacy, as assessed by patient-reported outcomes, safety and pharmacokinetics, of CTP13 and reference infliximab in patients with ankylosing spondylitis: 54-week results from the randomized, parallel-group PLANETAS study. Arthritis Res Ther 2016; 18:25.

65. Yoo DH, Racewicz A, Brzezicki J, Yatsyshyn R, Arteaga ET, Baranaus- kaite A, et al. A phase III randomized study to evaluate the efficacy and safety of CT-P13 compared with reference infliximab in patients with active rheumatoid arthritis: 54-week results from the PLANETRA study. Arthritis Res Ther 2016;18:82.

66. Aarden L, Ruuls SR, Wolbink G. Immunogenicity of anti-tumor necrosis factor antibodies toward improved methods of anti-antibody measurement. Curr Opin Immunol 2008;20:431-5.

67. Wolbink GJ, Aarden LA, Dijkmans BA. Dealing with immunogenicity of biologicals: assessment and clinical relevance. Curr Opin Rheumatol 2009;21:211-5.

68. Hart MH, de Vrieze H, Wouters D, Wolbink GJ, Killestein J, de Groot ER, et al. Differential effect of drug interference in immunogenicity assays. J Immunol Methods 2011;372:196-203.

69. Salimi-Moosavi H, Rathanaswami P, Rajendran S, Toupikov M, Hill J. Rapid affinity measurement of protein-protein interactions in a microfluidic platform. Anal Biochem 2012;426:134-41.

70. Guideline on immunogenicity assessment of biotechnology-derived therapeutic proteins. EMEA/CHMP/BMWP/14327/2006; 7-9.

71. Guideline on immunogenicity assessment of monoclonal antibodies intended for in vivo clinical use. EMA/CHMP/BMWP/86289/2010 (Updated 2010); 9-12.

72. Guidi L, Pugliese D, Panici Tonucci T, Berrino A, Tolusso B, Basile M, et al. Therapeutic drug monitoring is more cost-effective than a clinicallybased approach in the management of loss of response to infliximab in inflammatory bowel disease: an observational multicentre study. J Crohns Colitis 2018;9:1079-88.

73. Bader L, Solberg SM, Kaada SH, Bolstad N, Warren DJ, Gavasso S, et al. Assays for infliximab drug levels and antibodies: a matter of scales and categories. Scand J Immunol 2017;86:165-70.

74. Steenholdt C, Ainsworth MA, Tovey M, Klausen TW, Thomsen OO, Brynskov J, et al. Comparison of techniques for monitoring infliximab and antibodies against infliximab in Crohn's disease. Ther Drug Monit 2013;35:530-8.

75. Steenholdt C, Bendtzen K, Brynskov J, Thomsen OO, Ainsworth MA. Clinical implications of measuring drug and anti-drug antibodies by different assays when optimizing infliximab treatment failure in Crohn's disease: post hoc analysis of a randomized controlled trial. Am J Gastroenterol 2014;109:1055-64.

76. Vande Casteele N, Buurman DJ, Sturkenboom MGG, Kleibeuker JH, Vermeire S, Rispens T, et al. Detection of infliximab levels and anti-infliximab antibodies: a comparison of three different assays. Aliment Pharmacol Ther 2012;36:765-71.

77. Ananthakrishnan AN. Epidemiology and risk factors for IBD. Nat Rev Gastroenterol Hepatol 2015;12:205-17.

78. Enciso IP, Paredes LF, Sanchez-Ramon S, Mendoza JL, Cristina Alba, Olivares D, et al. Comparison of four assay kits for measuring infliximab trough levels and antibodies to infliximab in patients with inflammatory bowel disease. Gastroenterology 2016;4:S415.

79. Guiotto C, Daperno M, Frigerio F, Vizzini M, Cerruti R, Ercole E, et al. Clinical relevance and inter-test reliability of anti-infliximab antibodies and infliximab trough levels in patients with inflammatory bowel disease. Dig Liver Dis 2016;48:138-43.

80. Lee MW, Connor S, Ng W, Toong CM. Comparison of infliximab drug measurement across three commercially available ELISA kits. Pathology 2016;48:608-12.

81. Malickova K, Duricova D, Bortlik M, Hind'oš M, Machková N, Hrubá V, et al. Serum trough infliximab levels: a comparison of three different immunoassays for the monitoring of CT-P13 (infliximab) treatment in patients with inflammatory bowel disease. Biologicals 2016;44:33-6.

82. Schmitz EM, van de Kerkhof D, Hamann D, van Dongen JL, Kuijper PH, 
Benucci M, et al.

Laboratory monitoring of biological therapies

ANNALS OF

LABORATORY MEDICINE

Brunsveld L, et al. Therapeutic drug monitoring of infliximab: performance evaluation of three commercial ELISA kits. Clin Chem Lab Med 2016;54:1211-9.

83. Van Bezooijen JS, Koch BC, Doorn MV, Prens EP, Gelder TV, Schreurs MW. A comparison of three assays to quantify infliximab, adalimumab and etanercept serum concentrations. Ther Drug Monit 2016;38:432-8.

84. Freeman K, Taylor-Phillips S, Connock M, Court R, Tsertsvadze A, Shyangdan $\mathrm{D}$, et al. Test accuracy of drug and antibody assays for predicting response to antitumor necrosis factor treatment in Crohn's disease: a systematic review and meta-analysis. BMJ Open 2017;7:e014581.

85. Pérez I, Fernández L, Sánchez-Ramon S, Alba C, Zatarain A, Cañas M, et al. Reliability evaluation of four different assays for therapeutic drug monitoring of infliximab levels. Ther Adv Gastroenterol 2018;11:1-10.

86. Afonso J, de Sousa HT, Rosa I, Carvalho J, Dias CC, Magro F. Therapeutic drug monitoring of CT-P13: a comparison of four different immunoassays. Therap Adv Gastroenterol 2017;10:661-71.

87. Schmitz EMH, Benoy-De Keuster S, Meier AJL, Scharnhorst V, Traksel RAM, Broeren MAC, et al. Therapeutic drug monitoring (TDM) as a tool in the switch from infliximab innovator to biosimilar in rheumatic patients: results of a 12-month observational prospective cohort study. Clin Rheumatol 2017;36:2129-34.

88. Afonso J, Lopes S, Goncalves R, Caldeira P, Lago P, Tavares de Sousa H, et al. Proactive therapeutic drug monitoring of infliximab: a comparative study of a new point-of-care quantitative test with two established ELISA assays. Aliment Pharmacol Ther 2016;44:684-92.

89. Magro F, Afonso J, Lopes S, Coelho R, Gonçalves R, Caldeira P, et al. Clinical performance of an infliximab rapid quantification assay. Ther Adv Gastroenterol 2017;10:651-60.

90. Nasser Y, Labetoulle R, Harzallah I, Berger AE, Roblin X, Paul S, et al. Comparison of point of care and classical immunoassay for the monitoring Infliximab and antibodies against Infliximab in IBD. Dig Dis Sci 2018; 63:2714-21.

91. Meacci F, Manfredi M, Infantino M, Grossi V, Benucci M. Anti Etanercept and anti SB4 antibodies detection: impact of the assay method. Ann Rheum Dis 2016;75:e39.

92. Meacci F, Manfredi M, Infantino M, Grossi V, Benucci M. Infliximab and CT-P13 immunogenicity assessment in PLANETAS and PLANETRAS main and extension studies: utility of laboratory methods description. Ann Rheum Dis 2016;75:e62.

93. Qin X, Rui J, Xia Y, Mu H, Song SH, Raja Aziddin RE, et al. Multi-center performance evaluations of Tacrolimus and Cyclosporine electrochemiluminescence immunoassays in the Asia-Pacific region. Ann Lab Med 2018;38:85-94.

94. Choi R, Jeong BH, Koh WJ, Lee SY. Recommendations for optimizing tuberculosis treatment: therapeutic drug monitoring, pharmacogenetics, and nutritional status considerations. Ann Lab Med 2017;37:97-107. 